\title{
The nature of written language deficits in children with SLI
}

Running head:

The relationship between the oral and written language skills of children with SLI

Authors:

Clare Mackie and Julie E. Dockrell

Corresponding author:

Julie E. Dockrell

School of Psychology and Human Development

Institute of Education

20 Bedford Way

London WC1H 0AL

j.dockrell@ioe.ac.uk 


\begin{abstract}
Children with Speech and Language Impairment (SLI) have associated difficulties in reading decoding and reading comprehension. To date few research studies have examined the children's written language. The aim of the present study was to provide data, which would evaluate the nature and extent of the children's difficulties with writing, and to investigate the relationship between oral and written language. Eleven children with SLI were identified, with a mean age of 11 (age range 9:8-12:1) and were compared with a group of children matched for chronological age (CA) mean age 11:2 (age range 10-12.3) and language age (LA), with a mean chronological age of 7:3 (age range 6-9:8). All groups completed a language measure, the Bus Story Test of Continuous Speech (Renfrew, 1985), a standardised measure of writing, the Picture Story Language Test (Myklebust, 1965), and a reading assessment, the Wechsler Objective Reading Dimensions (Rust, Golombok \& Trickey, 1993). The writing assessment revealed that the SLI group wrote fewer words and produced proportionately more spelling and syntax errors than the CA group. There was no difference between the groups on a measure of the content of written language. The SLI group alsoproduced proportionately more syntax errors than the LA group. The relationships between oral language, reading and writing differed for the three groups. The SLI group revealed specific difficulties in the omission of verbs and verbal morphology. The nature and extent of the children's written language problems are considered in the context of difficulties with spoken language.
\end{abstract}




\section{Introduction}

Children with Specific Language Impairment (SLI) experience problems with the acquisition and processing of oral language. The most commonly used core criterion to identify children with SLI is that their language problems cannot be explained in terms of other cognitive, neurological or perceptual deficits (Bishop, 1992). Their problems are characterised by a protracted rate of language development as well as difficulties with particular subcomponents of the language system (see Bishop, 1997 and Leonard, 1998 for reviews). These problems also affect the processing of written text. Difficulties with word decoding and understanding written texts have been reported in a number of studies (Bishop \& Adams, 1990; Botting, Crutchley \& Conti-Ramsden, 1998; Stothard, Snowling, Bishop, Chipchase \& Kaplan, 1998) whilst, surprisingly, studies examining the children's written skills are rare. The current study aims to address this gap by considering the written language skills of children with SLI in relation to chronological and language-matched peers.

\section{Producing Written Text and the Potential Impact of Oral Language Problems}

Writing is a complex skill involving a number of linguistic and non-linguistic processes. Much of our understanding of the writing process has been based on the model developed by Hayes and Flower (1986; Hayes, 1996). In this model, the skilled writer is conceptualised as using the three recursive skills of translation, planning and reviewing to produce text. The model was derived from work with adults and therefore does not address how children become good writers. Berninger and colleagues in the USA have adapted the model to address how children learn to write (Swanson \& Berninger, 1994). In children, it is known that translation skill, (i.e. putting your words on the page) develops first, with planning and reviewing emerging later, once translation skills are well embedded. Children's writing 
includes very little that can be classed as either planning or reviewing (Bereiter \& Scardamalia, 1987). There is, therefore, evidence that investigations that focus on the initial stages of writing ought to be at the translation level.

The translation process can be split into two components, called text generation and transcription (Berninger, 1999). Text generation involves turning ideas into units of language - into the words, sentences and larger units of discourse produced within working memory, whereas transcription comprises "the cognitive and physical acts of forming written (as opposed to spoken) representations of text" (McCutchen, 1995:128). Handwriting processes, for example, would fall under transcription. For all children the process of learning to write fluently and coherently is an extended process. For example, Perera (1984) carried out an indepth analysis of the structure of children's writing. She distinguished some of the characteristics of younger writers, describing their texts as often muddled and incoherent as the writer lost his/her train of thought, leading to repetitions, failure of agreement between tenses and inconsistent use of pronouns. Young writers were also described as being more likely to use "and" rather than other connectives, to use simple active verbs and to use constructions more acceptable in speech. In sum, developing text generation skills in typical learners is an extended process that is mirrored by a range of errors in their written text, errors that are no longer common in their oral language. Text generation is reported by teachers as being particularly difficult for children with SLI (Dockrell \& Lindsay, 2000).

There are a number of reasons to predict that children with SLI would experience difficulties with writing and text generation specifically. The high cognitive demands placed on the individual in creating written text may overload a language system that is, arguably, reduced in processing capacity (Ellis Weismer, Evans \& Hesketh, 1999; Montgomery, 2000; Windsor 
\& Hwang, 1999). Such difficulties would lead to reduced length of texts and higher levels of errors than age matched peers. There are also reasons to predict particular patterns of errors in the written text itself. The reduced lexical knowledge experienced by some children with SLI may impact directly on the children's written outputs. More advanced writing is associated with a greater number of different words (Beard, 1986), increases in the number of adjectives (Wells \& Chang, 1986) and an increased number of adverbs and adverbial phrases (Perera, 1984). Thus, limits in vocabulary are likely to influence both the length and content of the written texts of children with SLI. In contrast the grammatical complexity of the written outputs may be influenced by the morphological (Leonard, Eyer, Bedore \& Grela, 1997) and the syntactic problems experienced by the children (van der Lely \& Christian, 2000; van der Lely \& Ullman, 2001). Grammatical difficulties may manifest themselves in writing through, for example, the construction of simple sentences and the omission of prepositions, articles and verbs. Associated problems with phonology and reading may also impact on writing through increased numbers of spelling errors (Clarke-Klein, 1994; Lewis \& Freebairn, 1992; Treiman, 1991) or the lack of experience with written narratives (Fitzgerald \& Shanahan, 2000). Thus, there are a variety of indirect reasons to predict that children with SLI will experience difficulties with generating written text. The relationship between oral language performance and written language performance requires systematic investigation to identify specific vulnerabilities and to guide evidence based interventions.

\section{Previous Research on the Written Language Skills of Children with Language}

\section{Impairment}

Three studies provide direct evidence of the written language performance of children with language learning difficulties (LLD). Gillam and Johnston (1992) studied both spoken and written narratives of 9-12 year old children with and without LLD. The sample consisted of 
10 children with LLD and three matched comparisons: a group matched for chronological age, a group matched for language age (as measured by performance on a sentence imitation task) and a group matched for reading age. The children were asked to produce both a spoken and written story in response to a picture. The results indicated that producing a written narrative was significantly harder than producing an oral narrative. This was true for all groups, with fewer morphemes and prepositions occurring in written as compared to spoken narratives. No differences were found between the groups on vocabulary, content, organisation or the number of prepositions. The only measure that differentiated the LLD group from all the comparison groups in the writing measure was the number of grammatical errors in complex T-units, that is sentences that include a main clause and a subordinating clause (Hunt, 1970). These results support the view that the children are experiencing a particular vulnerability in linguistic form, as evidenced by their grammatical errors. More recently two studies by Windsor and her colleagues (Scott \& Windsor, 2000; Windsor, Scott \& Street, 2000) have explored in greater detail the written language of children with language learning disabilities. In the first study 20 language learning disabled students, many of whom were receiving or had received special education for a spoken language impairment, were matched with chronological and language age matches. Language age scores for matching were derived from a composite expressive and receptive language measure (age appropriate version of the Test of Language Development-2: Hammill \& Newcomer, 1988; Newcomer \& Hammill, 1988). Participants produced oral and written summaries of two educational videos. The task was designed to reflect typical classroom demands and the "children were asked to summarise new and extensive information" (Scott \& Windsor, 2000:336). As in the Gillam and Johnston study (1992) it was the percentage of written utterances containing grammatical errors that clearly separated the children with LLD from their language age matched peers. In a related study, with the same sample group, the key aspect that differentiated the children 
with LLD and their language age matched peers was the total number of verb composite errors (Windsor, Scott \& Street, 2000). Windsor et al (2000) argue that this finding complements similar findings for spoken language, as omission of -ed is a particular deficit in the spoken language of children with SLI (Marchman, Wulfeck \& Ellis Weismer, 1999; Rice, Wexler \& Cleave, 1995). These three studies provide important empirical evidence of the impact of children's oral language difficulties on written language, when asked to produce a story or relate information. For the majority of measures performance is commensurate with language age matched peers but not chronological age matched peers. Moreover, the results highlight specific limitations with written syntax beyond those of language age matched peers for children with language learning disabilities. These limitations may characterise the children's core linguistic deficit.

Given the range of language related difficulties experienced by children with specific language impairment it is important to consider the extent to which these conclusions are valid with different language impaired populations and for different types of language comparisons. All three studies described have included participants with language learning disabilities, not all of whom had a history of language difficulties. These children's difficulties may not be specific to language, reflecting more general difficulties in generating written text experienced by children with learning disabilities (Graham, 1990; MacArthur \& Graham, 1987). This broader sample may obscure the impact of the language processing deficits and minimise the correlates of oral language problems. By corollary the ways in which language matches are identified raise conceptual issues. Participants can be matched on an overall language age measure, as in the Windsor studies, or a more specific measure such as sentence repetition as in the Gillam and Johnston study. Neither of these matches would capture the ability to generate ideas in oral language. Matching children a priori on their 
production of oral narratives and then testing their performance on written narratives is a further way to identify linguistic features of writing that are central to the children's problems. In addition, as suggested by Windsor et al (2000), investigations of the written text of children with language difficulties should include an analysis of the types of errors made as well as the frequency of errors.

\section{Purpose}

The current study develops previous work by exploring the delays and differences in the written output of children with SLI. We consider whether the written narratives of children with SLI can be distinguished from those of children matched with a similar level of oral narrative ability and those of their age matched peers. Specific research questions centered on a) the pattern of performance across the three groups in terms of fluency, content and accuracy of written text b) the interrelationships between oral language, reading and writing performance c) the nature of the errors produced by children with SLI. We hypothesised that the children with SLI would perform as well on a measure of content of written language as a language comparison group matched on expressive narrative language. However it was further hypothesised that the children with SLI would have specific difficulties with grammar, spelling and the length of their written samples. In comparison to a group of chronological age matched children it was hypothesised that the children with SLI would experience difficulties in all areas of written language including content.

To evaluate these predictions a writing assessment that examined each of the elements of written language was identified. To provide a robust test of these predictions a stimulus that did not require additional processing or that placed demands on working memory (Bishop, 1997; Gathercole \& Baddeley, 1990) was chosen. The Picture Story Language Test (PSLT) 
(Myklebust, 1965) was chosen as a method of assessing the written samples, as it met all the following criteria. The assessment directly measures the children's ability to generate a piece of original discourse, by asking the children to produce a story in response to a visual prompt. Appropriate comparisons can be made across different ages. In addition the measure includes an analytic scoring scheme examining content, productivity and syntax thereby addressing the three writing dimensions of concern for the present study. This type of scoring has been shown to introduce a higher level of reliability than those based only on one general holistic score (Wesby \& Clauser, 1999). An assessment that incorporated a visual prompt was chosen to ensure that the children's poor literacy or memorial skills did not compromise performance. As a direct comparison to the PSLT, the Bus Story Test of Continuous Speech (Renfrew, 1985) was chosen to measure oral language abilities. The Bus Story is an assessment which measures narrative ability and has been shown to be an indicator of early language ability that has strong relationships with future language and literacy performance (Stothard et al., 1998).

\section{Method}

\section{Participants}

The total sample consisted of 33 children, 11 children in each of three matched groups: (a) 11 children, ( 8 boys and 3 girls) mean age 11 (range 9:8-12:3) who were diagnosed with a Specific Language Impairment and were attending a special language school, (b) 11 typically developing children matched for chronological age and gender, mean age 11:2 (range 10:012:3) and c) 11 typically developing children matched for gender and language age (LA) on the Bus Story, mean age 7:3 (range 6:0-9:8).

For all participants with SLI their diagnosis was confirmed by assessment with the Clinical Evaluation of Language Fundamentals-Revised (CELF-R: Semel, Wiig \& Secord, 1987). All 
students with SLI had total language scores on the CELF-R that were more than 2 SDs below the norm (British Standardisation). Nonverbal scores on the Raven's coloured matrices (Raven, Court \& Raven, 1983) were within the average range that is above the $25^{\text {th }}$ centile. These data confirmed the diagnosis of SLI. The Bus Story Test of Continuous Speech (Renfrew, 1985) was used to document each child's expressive narrative language. An example of each groups' transcript is given in Appendix A. Participants achieved an age equivalent score of 6:8 (range 4:6-8:5) on the Bus Story. Children's reading skills were assessed on the Weschler Objective Reading Dimensions (WORD: Rust, Golombok \& Trickey, 1993). As expected reading skills were delayed with a mean reading age of 7:2 (range 6:0-9:0).

The two groups of comparison children attended a local primary school. They had no identified language or learning difficulties and were selected by teachers as having attained average scores on curriculum assessments. The three groups did not differ in non-verbal ability, as measured by Raven's matrices $F(2,30)=.80, p=.46)$. The CA comparison children were matched within an average of two months and did not differ from the children with SLI in age $(t(20)=.54, p=.59)$. The LA comparison children were matched with the children with SLI on language age scores from the Bus Story information score. All the children were matched within an average of 3.5 months. The Language age matches did not differ significantly from the children with SLI on the Bus Story information measure raw scores $(t(20)=.66, p=.50)$ or on the Bus Story sentence length raw scores $(t(20)=$ $\mathbf{1 . 1 5}, \boldsymbol{p}=\mathbf{. 2 6}$ ). The children's performance on the WORD reading test was matched within a 3 month window, they also did not differ on the WORD reading test $(t(20)=.20, p=.84)$. Scores for the three groups of children on the language, reading and cognitive measures, are presented in Table 1. 
INSERT TABLE 1 ABOUT HERE

\section{Instruments}

There were two language assessments administered to the children as part of this study: the Bus Story Test of Continuous Speech (Renfrew, 1985) and the CELF-R (Semel et al., 1987). The Bus Story involves the examiner telling the child a short story about a bus while the child looks through a series of pictures, which illustrate the story. The child must then retell the story as accurately as possible using the pictures as cues. The stories were audiotaped and transcribed. The children's oral narratives were scored for the amount of information provided and for the length of each sentence, yielding an 'information score' and a 'sentence length score'. The CELF-R is a comprehensive language test covering a range of language functions including phonology, syntax, semantics, memory and word finding and retrieval. The British standardisation (CELF-R) is commonly used as part of the identification process for SLI in the UK. This measure provides both an expressive and receptive language score, which is totalled to yield an overall language score.

The WORD (Rust et al., 1993) is an individually administered test of single word reading accuracy between the ages of 6-16 years. A series of pictures and printed words are presented for the participant to decode; the test provides standard scores and reading age equivalents. The Raven's Matrices (Raven et al., 1983) is a non-verbal ability test, which presents the child with a series of patterns from which a 'piece' is missing. The child is instructed to look at the pattern and select (from six alternative 'pieces' printed below the pattern) the piece that can complete the pattern. 
The Picture Story Language Test (PSLT) (Myklebust, 1965) was used to assess the children's written skills. The PSLT is a standardised writing assessment for children and older adolescents between the ages of 6-17 years. It incorporates a visual prompt, which enables the children to generate a piece of original text.

\section{Procedure}

Each child was tested individually over a period of 4-5 days. The first author administered each assessment, at a separate time and according to the standard format. For the PSLT the child was asked to look at the picture carefully and then to write a story about the picture. The picture was placed in a central position where it could be easily seen throughout the task. The PSLT states that if a child asked questions, for example should it have a title, the reply would be non-directive "if you want the story to have a title, it can" (Myklebust, 1965: 93). The children were allowed 30 minutes to complete the story, if the child finished in a shorter period the time was recorded. At the end the examiner, together with the child, read the story out loud in order to ascertain the child's meaning. This also enabled the examiner to decipher any words spelt incorrectly. The order of the assessments was counterbalanced across participants with half the children undertaking the language assessments first and the other half undertaking the writing measure first.

\section{Writing Analysis}

The PSLT is evaluated with three scales: productivity, syntax and abstract-concrete, which examines written content.

\section{Productivity}

The total number of words represented the productivity scale 


\section{Syntax}

The syntax scale provides a total count of errors in grammatical construction and morphological features. Within each of these categories error types, additions, omissions and substitutions, are scored, for example,

Grammatical construction:

An addition of a word, which interferes with meaning 'the guard more was called' Omission of a word that is obligatory in the context 'a boy (is) playing with toys' Substitution of word, which can include errors of verb or tense 'the space ship break his toy'.

Morphological factors:

Addition of a grammatical inflection 'there are toys shoes'

Omission of a correct inflection 'the ground is float_', 'the boy is play_'

Substitution of a grammatical inflection 'he is plays with his toys'

The system of determining the intended meaning of the sentences, therefore to deduce which category of syntax errors the child has made, was through the following criteria. In some cases the intended meaning was deduced from the picture, for example if a sentence was produced 'there are book on the table'- this can be categorised as either substitution of verb are/is or omission of plural $-\mathrm{s}$, as the picture contains more than one book- the omission of grammatical morpheme was taken as the most likely intended meaning. In addition the children were instructed to read aloud what they had written and in some cases they would produce the correct grammatical morpheme, even though it was omitted in their writing. The final error score is divided by the total number of words, which allows an error analysis corrected by the length of the writing sample. 


\section{Content}

The abstract-concrete scale consists of a series of five levels of definitions, constituting criteria to be used in rating the level of abstract thought or ideation being conveyed. Level 1, constitutes only a series of unrelated letters or words, level 2 assigns a number of scores whereby the student only describes the picture. Level 3 involves a more imaginative setting to the story, representing the beginning of a narrative. Level 4 and 5 constitute stories, which are abstract, where the picture serves more as a point of reference, rather than being central to the story itself. Factors of language proficiency are ignored; only the content or quality of the ideation is evaluated, (See pages 135-146 in the manual for further clarification).

\section{Fluency}

Each child was allowed 30 minutes to complete the writing task but not all children used the allocated time. To produce a fluency measure based on output the time each child had taken to complete the PSLT was divided by the total number of words to represent a measure of fluency.

\section{Classification of Spelling Errors}

Initially all spellings were determined to be correct or incorrect. Those that were incorrect were further categorised according to phonological and orthographic accuracy. A scoring scheme initially developed by Bruck and Waters (1988), and Bruck, Treiman, Caravolas, Genesee and Cassar (1998) was used to further analyse error patterns. This scheme allowed for an analysis of error patterns when children were producing different word types, rather than a standardised spelling assessment. A spelling was classified as either phonologically accurate or phonologically inaccurate and as either orthographically accurate or orthographically inaccurate. Each error therefore received 2 ratings. A phonologically 
accurate error was defined when it could be pronounced like the target word by the use of grapheme-phoneme correspondences, for example bak instead of back. A phonologically inaccurate error was defined as not having a possible sound to grapheme correspondence in English, for example clars instead of clouds. Typically these errors involved substitution of wrong sounds, insertion of sounds or deletion of sounds. An orthographic accurate error was categorised as an error, but where the sequence of letters is permissible in English words, for example allways instead of always. An orthographic inaccurate error was defined as a misspelling containing a sequence of letters that is illegal, which would include positional restriction, for example drak instead of dark.

\section{Coding Reliability}

Reliability checks were performed on all writing samples, on all scales, by the first author and a postgraduate research officer and in the case of the abstract-concrete scale by an additional researcher who was a trained primary school teacher. All of the writing samples were scored for all scales. The procedures for scoring followed the detailed instructions in the PSLT. In the case of an inter-rater disagreement the scores of the first author was used. Mean reliability for the syntax scale was $89 \%$ and for the abstract-concrete scale mean reliability 92\%. With regard to judging whether a word was spelt correctly or incorrectly reliability was also $100 \%$, across all error categories mean reliability was $91 \%$. 


\section{Results}

The results are presented in three sections. Section one examines the performance of the children on the PSLT. Section 2 describes the relationships between the written and oral language measures and the different measures of written language performance. Finally to explore further the nature of the children's error patterns the third section provides a detailed analysis of the specific components of the syntax scale, whole word and word ending errors.

\section{Patterns of Difference in Writing Task Performance across Children with SLI and LA and CA Matches}

\section{INSERT TABLE 2 ABOUT HERE}

Examples of the SLI, CA and LA comparison groups writing samples are shown in Appendix B. Table 2 presents the performance of the groups on the writing test. Results of a one-way ANOVA, corrected for Type I error using a Bonferroni correction (using a probability level of $.01)$, revealed a statistically significant difference between the three groups on the total number of words written $F(2,30)=7.35, p=.003$ (partial eta squared .32 ). A series of Tukey HSD post hoc analyses indicated that the children with SLI were producing significantly fewer written words than the CA group $(p=.002)$ but not the LA group $(p=.61)$. The LA group did not differ significantly from the CA group $(p=.027)$.

The mean writing time for the SLI group on the writing task was 14.55 minutes $(S D=5.68)$, for the CA group 12.73 minutes $(S D=4.10)$ and for the LA group 15.45 minutes $(S D=4.72)$. There was no statistically significant difference between the groups $(F(2,30)=.89, p=.42)$ on the time taken to complete the writing task. Fluency of writing across the groups, based on the number of words produced per minute, was statistically significantly different $(F(2,30)=$ $7.42, p=.002$, (partial eta squared .33)). The children with SLI were producing significantly 
fewer written words than the CA group $(p=.004)$ but not the LA group $(p=.94)$. The LA group also wrote fewer words than the CA group $(p=.01)$. Thus in terms of both total number of words and fluency the children with SLI differed significantly from their CA peers but not their LA peers.

The mean total number of syntax errors differed significantly across groups $(F(2,30)=6.67$, $p=.004$ (partial eta squared .30)) with the SLI group producing more errors $(M=5.91, S D=$ 4.35), than the CA group $(M=1.64, S D=1.29)$ and the LA group $(M=2.45, S D=2.21)$. In order to reflect a true syntax error score, the total number of errors divided by the total number of words was used to create a proportion score. The groups differed statistically significantly in the proportion of syntax errors produced $F(2,30)=9.98, p=.001$ (partial eta squared .39). Post hoc tests revealed that the SLI group produced statistically significantly more errors than both the CA group $(p=.001)$ and the LA group $(p=.003)$. However there was no statistically significant difference between the CA group and the LA group $(p=.86)$ in their proportion of syntax errors.

The total number of spelling errors made by the SLI group $(M=5.36, S D=5.61)$ did not differ from the CA group $(M=3.27, S D=4.17)$ or the LA group $(M=7.91, S D=7.67), F(2$, $30)=1.65, p=.20$. In order to reflect an error rate in relation to words produced the total number of words was divided by the total number of words spelt incorrectly. Due to unequal variance the nonparametric equivalent, the Kruskal-Wallis test, was used to compare the proportion of spelling errors. The groups differed statistically significantly in the proportion of spelling errors produced $X^{2}(2)=9.88, p=.007$, (partial eta squared .19$)$. When comparing the groups individually the Mann-Whitney test was used. There were no statistically significant differences between the SLI and the CA group $(U(11)=32.00, p=.06)$ or 
between the SLI and the LA group $(U(11)=48.00, p=.43)$. However the LA group produced statistically significantly more errors than the CA group $(U(11)=11.00, p=.001$, Cohen's $d=1.65)$.

There was no statistically significant difference between the groups on a measure of content $F(2,30)=3.54, p=.042$. However the children with SLI had lower content scores than the CA group $(p=.026)$ but not the LA group $(p=.24)$. There was no significant difference between the LA group and the CA group $(p=.52)$.

\section{Patterns of Relationship between Measures of Oral and Written Language}

To examine the relationship between the written measures and the children's oral language ability, partial correlational analyses were carried out separately for the three groups of participants, controlling for age. All correlations were corrected for Type I error using a Bonferroni correction (using a probability level of .006). All correlations are presented in Table 3 for the SLI group, Table 4 for the CA group and Table 5 for the LA group.

Surprisingly, as Table 3 shows, for the SLI group there were no statistically significant correlations between oral language and any measure of writing, between reading and oral language or between the different measures of written language. However, there was a statistically significant negative relationship between word reading and the proportion of spelling errors produced $(r(11)=-.82, p=.002)$, indicating that the higher the score on word reading the lower the proportion of spelling errors were produced.

INSERT TABLE 3 ABOUT HERE 
Patterns for the two comparison groups differed from the children with SLI. For the CA group there was no statistically significant correlation between the oral language measure and any measure of writing at the .006 corrected level.

\section{INSERT TABLE 4 ABOUT HERE}

The LA matches also did not demonstrate any statistically significant correlations between word reading, oral language and any measure of writing. However a positive relationship was revealed between the total number of words and fluency $(r(11)=.80, p=.005)$.

None of the groups demonstrated a relationship between oral language, as measured by the Bus Story, and written language. However, for both the comparison groups there were relationships between written content and written word production. In contrast the amount and fluency of the writing of the children with SLI were not significantly related to content. This raises the question of ways in which the written productions of the groups of children differ.

\section{INSERT TABLE 5 ABOUT HERE}

\section{Spelling errors}

The SLI group $(M=.58, \mathrm{~S} D=.43)$ produced proportionately more phonologically inaccurate errors than both the CA $(M=.09, S D=.18)$ and the LA $(M=.37, S D=.34)$ group. In addition for orthographic errors the SLI group $(M=.34, S D=.38)$ produces proportionately more orthographic inaccurate errors than the CA $(M=.01 S D=.03)$ and the LA $(M=.22, S D$ $=.31)$ group. Results of a one-way ANOVA, corrected for Type I error using a Bonferroni correction (probability level of .01) revealed a statistically significant difference between the groups in the proportion of phonologically inaccurate errors $F(2,30)=5.88, p .007$ (partial 
eta squared .28). Post hoc tests revealed statistically significant difference between the SLI and CA group $(p=.005)$ but not the SLI and LA group $(p=.32)$ or between the CA and LA group $(p=.14)$. For the proportion of orthographic inaccurate spelling errors, a statistically significant difference was revealed between the groups $F(2,30)=3.75, p=.035$ (partial eta squared .20), though not at the corrected .01 level. Post hoc tests showed a small statistically significant difference between the SLI group and the CA group $(p=.03)$ but not between the SLI group and the LA group $(p=.63)$ or between the CA and LA group $(p=.20)$.

\section{Specific Syntax Measures}

As we have shown the major difference between the children with SLI and their LA matched peers is in terms of the proportion of syntax errors produced. To explore these differences further this section compares the children's performance on the two aspects of the syntax scale - word usage and word endings. Within each of these categories the specified error types included additions, omissions and substitutions. Table 6 presents the proportion of whole word addition, omission and substitution errors. As the table shows children with SLI produced more errors of all types in comparison to both CA and LA matches.

\section{INSERT TABLE 6 ABOUT HERE}

The Kruskal-Wallis test was used, owing to unequal variance and data were corrected for the possibility of a Type I error using a Bonferroni correction (using a probability level of .01). The three groups differed statistically significantly in the proportion of whole word addition errors produced $X^{2}(2, N=11)=10.56, p=.005$, (partial eta squared .23). Comparisons between the groups using the Mann-Whitney demonstrated that the children with SLI were producing significantly more whole word addition errors than the CA group $(U(11)=24.00$, 
$p=.016$, partial eta squared .29) but not the LA group $(U(11)=55.00, p=.75)$. The LA group produced more whole word addition errors than the CA group $(U(11)=18.00, p=$ .004 , partial eta squared .31). The groups also differed in the proportion of whole word omission errors produced $X^{2}(2, N=11)=10.26, p=.006$ (partial eta squared .15$)$. The SLI group produced a greater proportion of whole word omission errors than the CA group ( $U$ $(11)=24.00, p=.016$, partial eta squared .10$)$ and the LA group $(U(11)=21.00, p=.008$, partial eta squared .19). There was no statistically significant difference between the CA and the LA group $(U(11)=47.00, p=.40)$. In contrast there was no statistically significant difference between the three groups on the proportion of whole word substitution errors $\left(X^{2}\right.$ $(2, N=11)=2.60, p=.27)$.

A descriptive analysis of the whole word syntax errors made suggested that errors produced by the SLI group occurred specifically for auxiliary verbs, which constituted the majority of whole word omission errors (33.3\%). Other omissions included prepositions (23.8\%); pronouns $(23.8 \%)$; and conjunctions $(9.5 \%)$, with definite articles and adjectives comprising a further $4.8 \%$. The CA matched group produced 9 whole word omissions, with 2 instances of a preposition and an adverb, and a single instance of an auxiliary verb, an intransitive verb, a pronoun and an indefinite article. The LA group produced only three whole word omission errors; none of these was a verb error ( 2 pronouns and one adjective).

\section{INSERT TABLE 7 ABOUT HERE}

Table 7 presents the performance of the groups on the proportion of word ending errors. As no word ending addition error was produced by the LA group, a t-test was performed between the SLI and CA group; no statistically significant difference was revealed between the two groups $(\mathrm{t}(20)=1.87, \mathrm{p}=.85)$ on the proportion of word ending addition errors. There was a 
small statistically significant difference between the groups on the proportion of omission of word ending errors $F(2,30)=4.34, p=.022$ (partial eta squared .22 ), though not at the .01 level. Post Hoc tests again revealed a small statistically significant difference between the SLI group and both the CA group $(p=.043)$ and the LA group $(p=.04)$ however not at the .01 level. There was no statistically significant difference between the CA and the LA group ( $p=$ .99). The SLI group omitted word endings that were progressive -ing (47\%) and past tense (6\%) a further $47 \%$ were omissions of the plural $-s$. The CA and LA groups produced only omissions of the plural $-\mathrm{s}$, with the CA group producing three instances and the LA group only one instance.

\section{Discussion}

The purpose of this study was to investigate the written compositions produced by schoolaged children with SLI, in comparison to their CA and LA matched peers. Our first aim was

to evaluate the pattern of written performance across the three groups. Secondly, we aimed to investigate the relationship between the children's oral language, reading and writing. Thirdly, we aimed to examine the nature of the written errors produced by the children with SLI. It was predicted that the children with SLI would be delayed in their written language skills. Specifically we expected that the content of the children's written narratives would be equivalent to that of their language age matched peers but that they would experience greater problems with grammar, spelling and length than those of their language matched peers. In comparison to age matched peers, it was predicted they would experience difficulties in all areas of written output. It was expected that the level of the children's oral language skills, as measured by the Bus Story, would be positively related to the content and length of their written output. 


\section{Assessment of Written Language Performance across the Three Groups}

All groups spent a similar amount of time in producing their texts. The SLI group produced written stories, which were shorter in length than the CA matched group but not the LA matched group. This is consistent with studies citing productivity as a problem for children with language difficulties (Scott \& Windsor, 2000) and learning difficulties (Graham, 1990). However in contrast to earlier work (Scott \& Windsor, 2000), the children with SLI also produced fewer words per minute than their CA peers but not their LA peers. There are a number of possible explanations of this contrasting result. The reduced rate of written production may reflect the reduced processing resources found in the oral language of the children with SLI. Alternatively, the different tasks used in this study may have reduced the processing demands for the typically developing children such that they were able to produce their written work more fluently and automatically. The children's performance was not constrained by a time limitation since the majority of children completed the task with more that 15 minutes remaining. Thus, there is preliminary evidence that the children with SLI were having more difficulty getting their ideas on paper than children of a comparable chronological age. Although the amount of text produced was similar to language age peers it is important to note that the children with SLI had on average four more years of formal education and by corollary significantly more practice (and instruction) in writing than the LA matches. Nonetheless the content, as assessed by the current measures, was equivalent across the three groups, although there was a trend suggesting that the SLI group were producing fewer ideas than the CA group. In contrast, specific problems were evident in the children's written syntax. On this measure both LA and CA peers were performing more accurately. It would therefore appear that the children in the SLI group were capable of producing abstract and imaginative stories, albeit more slowly, despite having difficulties with the language of writing. 
Surprisingly there was no statistically significant difference between the children with SLI and the two comparison groups on the proportion of spelling errors produced. Qualitative analysis from reports of the SLI children suggested that they wrote words that they could spell, rather than attempt words, which they could not. Children would explicitly note that they could not spell a word and choose a similar but simpler word to spell. No such statements were recorded from the CA or LA groups. Thus, the lack of difference in spelling accuracy may reflect a strategy used by the children with SLI rather than a similar level of spelling performance per se. This interpretation is further supported by the types of errors produced by the three groups of children. These errors revealed that the children with SLI made more phonological errors than both the CA and the LA groups. Research has accumulated which shows the importance of phonological processing deficits in causing the literacy difficulties of children. These deficits are common in children with SLI and appear to be revealed in the specific difficulties with the phonological component of their spellings but not in their overall performance on the current task.

\section{Relationships between oral language, reading and writing}

Assessments of the relationships between language, literacy and word reading for the three groups revealed some unexpected patterns. No relationships were found in any of the three groups between the oral language measures and the written language measure. This lack of sensitivity of the standardised measures is only evident for oral language. In contrast reading accuracy as measured by the WORD was negatively associated with spelling errors for both the SLI and CA groups, confirming the conventional link between reading and spelling (Caravolas, Hulme \& Snowling, 2001). Moreover for the CA group reading accuracy was related to the children's scores on their content of written language. Of particular interest are 
the interrelationships between the writing measures for both the language age and chronological age matched peers. These indicate that for typical development the writing measures are associated and a developmental relationship between reading and writing was evident. Thus for the younger children the relationships were solely within the written language measure whereas for the older children reading began to feature as an associated variable. For the children with SLI no associations were evident either between the writing measures or between reading and writing. Such a pattern of results suggests that there are specific elements of the writing task that are more problematic than others for these children. This potential disparity in performance is evident when we consider the nature of the children's written errors.

\section{Nature of written errors produced by the SLI group}

The only statistically significant difference between the children with SLI and their language age matched peers was on the measure of syntax. The syntax scale was divided between whole word and word ending errors and further divided between addition, omission and substitution errors. Both the SLI and the LA group produced significantly more whole word addition errors than the CA group. The majority of these words were the conjunctive 'and', this reflects developmental patterns in writing described by Perera (1984). She has shown how such connectives are used repeatedly to outline a chronological sequence and to keep the discourse moving forwards by young writers. Perera states that as children mature linguistically their dependence on co-ordination decreases and the results of the current study corroborate these findings in a group of children with SLI.

The omission of whole words was an area that produced a statistically significant difference between the SLI group and both the CA and the LA group, but not between the LA and CA 
groups. This finding indicates that the omission of whole words within writing is a specific difficulty for children with SLI. The majority of whole word omission errors produced by the SLI group were auxiliary verbs, particularly the auxiliary be. Research has revealed that for children with SLI verb usage within their spoken language is particularly problematic (Fletcher \& Peters, 1984; Watkins, Rice \& Moltz, 1993) and recently studies have focused on the omission of auxiliary forms of be (Grela \& Leonard, 2000). The results of this writing analysis indicate that difficulties in auxiliary verbs are perpetuated in the children's written language. The extended optional infinitive (EOI) theory proposed by Rice et al (1995) would account for these difficulties. They propose that normally developing children pass through a period whereby they do not obligatorily mark tense in the main clause of sentences, they consider it to be optional. In the case of children with SLI, they are within this stage for a longer period of time. Therefore the omission of auxiliary $B E$ and DO or affixes on lexical stems such as third-person singular -s or regular past tense -ed, is attributable to the immaturity of grammatical constructions shown by children with SLI.

The findings also demonstrate difficulties with grammatical morphemes. Within the syntax scale the additions, omissions and substitutions of word endings were evaluated. It was again revealed that the only measure which differentiated the children with SLI from their chronological and language age matched peers was that of omission of word endings. No difference was revealed between the CA and LA groups on this measure. The SLI group produced omissions of past tense - ed, this adds further evidence to support the vulnerability of the children's use of morphology in written language. The SLI group also made more omissions of progressive inflection -ing and regular plural $-s$ errors. The theoretical EOI model does not predict these particular omissions of progressive -ing and plural -s. Rice 
et al (1995) states that in the case of progressive -ing the omission is likely to occur on the auxiliary verb preceding the lexical verb. This is inconsistent with the results found in the children's written samples. In addition noun plural -s, is not predicted by the EOI theory. Recently research has focused on the omissions of noun plurals in the spoken language of young children with SLI, indicating these errors are also present in oral language (Conti-Ramsden and Windfuhr, 2002).

Recently Treiman (1991) and colleagues (Treiman \& Bourassa, 2000) have suggested that young children who omit word endings such as past tense -ed are making an error in spelling rather than in syntax. However, this is not a parsimonious explanation of the current results. The children with SLI, in this study, made omissions of a range of grammatical morphemes, not only past tense -ed. In addition Trieman reports that in the majority spelling errors made by typically developing children 'ed' is substituted for a similar sounding phoneme for example /t/. In the current study none of the SLI group made such an error, whereas this error did occur in the writing of the LA group. In addition the SLI group often failed to produce the third person singular -s in their written compositions whereas children in the LA group were using this correctly. The omission of word ending errors in this sample is consistent with reports stating that children with SLI also have difficulty with both noun and verb morphology in their spoken language (Conti-Ramsden \& Windfuhr, 2002; Leonard, McGregor \& Allen, 1992; Rice \& Oetting, 1993) and recently in written narratives (Windsor et al., 2000).

\section{Limitations and future research}

The results of the current study indicate that children with SLI have deficits in written language in comparison to chronological and language matched peers and that, unlike their 
CA peers, reading skills at this point in development are not associated with written language. Moreover, there were no relationships between the different measures of writing for the children with SLI, this contrasted with the patterns evident in both comparison groups. The nature of the error patterns suggested that there were specific effects on productivity, syntax and spelling but not on a measure of content. In addition the use of verbs was particularly compromised: it was found that children with SLI omit verbs and morphological endings, which mirrors the difficulties experienced in their spoken language (Conti-Ramsden \& Jones, 1997; Leonard et al., 1992; Leonard, Miller \& Gerber, 1999). Children with SLI have the ability to produce imaginative stories, but not the linguistic resources in place to translate their ideas into written language.

These conclusions need to be considered in conjunction with the methods used in the current study and the level at which the difficulties experienced by the children with SLI were described. The PSLT provides the children with a single visual prompt and it has been argued that a sequence of pictures would elicit a response that is more cohesive and goal directed rather than a single visual prompt (Hooper et al. 1994). Thus, the context of the children's written narratives may have been limited by the stimuli, although there is no indication that the nature of the prompt influences the mechanics of writing, such as spelling and written grammar (Cole \& McLeod, 1999). A more sensitive measure of thematic style and organisation may well reveal different patterns of performance in the children with SLI. The reduced fluency of the children with SLI may further differentially affect tasks requiring a more cohesive and goal directed written piece, with potential further detrimental effects on grammar and spelling. 
Children with SLI are a heterogeneous group of children and further work should consider both the ways in which specific linguistic deficits impact on the production of written text and different assessments of their specific writing difficulties. The results indicate that these children have specific vulnerabilities with syntax and morphology. To what extent then do children who have difficulties with morphology and argument structure in oral language (King \& Fletcher, 1993; Thordardottir \& Elllis Weismer, 2002) differ from children whose deficits are specific to vocabulary or phonology? A more fine grained analysis of the children's oral language difficulties should be complemented by a similar analysis of the children's written language. For example, the use of written cloze procedures that tap particular linguistic forms would delineate further the ways in which the children's skills are compromised. Confirmation of such deficits and the ways in which they manifest themselves across a range of writing tasks would further our understanding of SLI and the writing process more generally. Moreover, such data could inform clinical practice and educational interventions.

The current study extends previous work with students with LLD in implicating oral language problems as a risk factor in producing written text for children with SLI. These children did not have specific problems in generating ideas. They did however, have marked difficulties in the grammar of writing. The nature of their errors were different to those of their CA and LA matched peers indicating a specific vulnerability in verb morphology and raise specific questions for further research examining the links between oral language and writing. 


\section{References}

Beard, R. (1986). Children's Writing in the Primary School. Sevenoaks: Hodder and Stroughten.

Bereiter, C., and Scardamalia, M. (1987). The Psychology of Written Composition. Hillsdale. NJ: Erlbaum.

Berninger, V. (1999). Co-ordinating transcription and text generation in working memory during composing: Automatic and constructive processes. Learning Disability Quarterly, 22, 99-112.

Bishop, D. V. M. (1992). The underlying nature of specific language impairment. Journal of Child Psychology and Child Psychiatry, 3, 1-64.

Bishop, D. V. M. (1997). Uncommon Understanding. Development and Disorders of Language Comprehension in Children. Psychology Press.

Bishop, D. V. M., and Adams, C. (1990). A prospective study of the relationship between specific language impairment, phonological disorders and reading retardation. Journal of Child Psychology and Child Psychiatry, 31, 1027-1050.

Botting, N., Crutchley, A., and Conti-Ramsden, G. (1998). Educational transitions of 7 year old children with SLI in language units: a longitudinal study. International Journal of Language and Communication Disorders, 33, 177-219.

Bruck, M., Treiman, R., Caravolas, M., Genesee, F., and Cassar, M. (1998) Spelling skills of children in whole language and phonics classrooms. Applied Psycholinguistics, 19, 669-684.

Bruck, M., and Waters, G. (1988). An analysis of the spelling errors of children who differ in their reading and spelling skills. Applied Psycholinguistics, 9, 77-92. 
Caravolas, M., Hulme, C., and Snowling, M. (2001). The foundations of spelling ability: Evidence from a 3-year longitudinal study. Journal of Memory and Language, 45, 751-774.

Clarke- Klein, S. M. (1994). Expressive phonological deficiencies: impact on spelling development. Topics in Language Disorders, 14, 40-55.

Cole, J. C and McLeod, J. S. (1999). Children's writing ability: The impact of the pictorial stimulus. Psychology in the Schools, 36, 359-370.

Conti-Ramsden, G., and Jones, M. (1997). Verb use in specific language impairment. Journal of Speech and Hearing Research, 40, 1298-1313.

Conti-Ramsden, G., and Windfuhr, K. (2002). Productivity with word order and morphology: A comparative look at children with SLI and children with normal language abilities. International Journal of Language and Communication Disorders, 37, 17-30.

Dockrell, J., and Lindsay, G. (2000). Meeting the needs of children with specific speech and language difficulties. European Journal of Special Needs Education, 15, 24-41.

Ellis Weismer, S. , Evans, J., and Hesketh, L. (1999). An examination of verbal working memory capacity in children with specific language impairment. Journal of Speech, Language and Hearing Research, 42, 1249-1260.

Fitzgerald, J., and Shanahan, T. (2000). Reading and writing relations and their development. Educational Psychologist, 35, 39-50.

Fletcher, P., and Peters, J. (1984). Characterising language impairment in children: An exploratory study. Language Testing, 1, 33-49.

Gathercole, S.E., and Baddeley, A.D. (1990). Phonological memory deficits in language disordered children: Is there a causal connection? Journal of Memory and Language, 29, 336360. 
Gillam, R., and Johnston, J. (1992). Spoken and written language relationships in language learning impaired and normally achieving school-age children. Journal of Speech and Hearing Research, 35, 1303-1315.

Graham, S. (1990). The role of production factors in learning disabled student's compositions. Journal of Educational Psychology, 82, 781-791.

Grela, B. G., and Leonard, L. B. (2000). The influence of argument structure complexity on the use of auxiliary verbs by children with SLI. Journal of Speech, Language and Hearing Research, 43, 1115-25.

Hammill, D. and Newcomer, P. (1988). Test of Language Development 2 Intermediate. Austin TX:Pro Ed.

Hayes, J. R. (1996). A new framework for understanding cognition and affect in writing. In C. M. Levy and S. Ransdell (Eds.), The Science of Writing: Theories, Methods, Individual Differences and Applications. (pp. 1-27). Hillsdale, NJ, England: Lawrence Erlbaum Associates.

Hayes, J. R., and Flower, L. S. (1986). Writing research and the writer. American Psychologist, 41, 1106-1113.

Hooper, S. R., Montogomery, J., Swartz, C., Reed, M. S., Sandler, A. D., Levine, M. D., Watson, T. E., and Wasileski, T. (1994). Measurement of written language expression. In G. R. Lyon (Ed.), Frames of Reference for the Assessment of Learning Disabilities: New Views on Measurement Issues (pp. 375-417), Baltimore, MD: Paul H. Brooks.

Hunt, K. (1970). Syntactic maturity in school children and adults. Monographs of the Society for Research in Child Development, 35, (Serial No. 134).

King, G., and Fletcher, P. (1993). Grammatical problems in school-age-children with specific language impairment. Clinical Linguistics and Phonetics, 7, 339-352. 
Leonard, L. B. (1998). Children with Specific Language Impairment. Cambridge. MA: The MIT Press.

Leonard, L. B., Eyer, J., Bedore, L., and Grela, B. (1997). Three accounts of the grammatical morpheme difficulties of English-speaking children with specific language impairment. Journal of Speech, Language and Hearing Research, 40, 741-753.

Leonard, L. B., McGregor, K. K., and Allen, G. D. (1992). Grammatical morphology and speech perception in children with specific language impairment. Journal of Speech and Hearing Research, 35, 1076-1085.

Leonard, L. B., Miller, C., and Gerber, E. (1999). Grammatical morphology and the lexicon in children with specific language impairment. Journal of Speech, Language and Hearing Research, 42, 678-689.

Lewis, B., and Freebairn, L. (1992). Residual effects of pre-school phonology disorder in grade school, adolescence and adulthood. Journal of Speech and Hearing Research, 35, 819-831.

MacArthur, C., and Graham, S. (1987). Learning disabled student's composing with three methods: Handwriting, dictation and word processing. Journal of Special Education, 21, $22-42$

Marchman, V. A., Wulfeck, B., and Ellis Weismer, S. (1999). Morphological productivity in children with normal language and SLI: a study of the English past tense. Journal of Speech, Language and Hearing Research, 42, 206-219.

Montgomery, J. (2000). Relation of working memory to off-line and real-time sentence processing in children with specific language impairment. Applied Psycholinguistics, 21, 117148.

Myklebust , H. R. (1965). The Picture Story Language Test. New York and London: Grune and Stratton. 
McCutchen, D. (1995). Cognitive processes in children's writing: Developmental and individual differences. Issues in Education, Contributions from Educational Psychology, 1, 123-160.

Newcomer, P. and Hammill, D. (1988). Test of Language Development 2 Primary. Austin TX:Pro Ed.

Perera, K. (1984). Children's Writing and Reading: Analysing Classroom Language. Oxford: Basil Blackwell.

Raven, J. C., Court, J. H., and Raven, J. (1983). Raven's Progressive Matrices and Raven's Coloured Matrices. London: H. K. Lewis.

Renfrew, C. E. (1985). The Bus Story: A Test of Continuous Speech. Oxford.

Rice, M. L., and Oetting, J. B. (1993). Morphological deficits of children with SLI. Evaluation of number marking and agreement. Journal of Speech and Hearing Research, 36, $1249-1257$.

Rice, M. L., Wexler, K., and Cleave, P. L. (1995). Specific language impairment as a period of extended optional infinitive. Journal of Speech and Hearing Research, 38, 850-863.

Rust, J., Golombok, S., and Trickey, G. (1993). Wechsler Objective Reading Dimensions. Sidcup, UK: Psychological Corporation.

Scott, C., and Windsor, J. (2000). General language performance measures in spoken and written discourse produced by school-age children with and without language learning disabilities. Journal of Speech, Language and Hearing Research, 43, 324-339.

Semel, E., Wiig, E. H., and Secord, W. (1987). Clinical Evaluations of Language Fundamentals-Revised. London: The Psychological Corporation, Harcourt Brace Jovanovich. Stothard, S. S., Snowling, M. J., Bishop, D. V. M., Chipchase, B. B., and Kaplan, C. A. (1998). Language-impaired pre-schoolers: A follow-up into adolescence. Journal of Speech, Language and Hearing Research, 41, 407-418. 
Swanson, H. L., and Berninger, V. (1994). Working memory as a source of individual difference in children's writing. In E. Butterfield (Ed.), Children's Writing: Toward a Process Theory of Development of Skilled Writing. (pp. 31-56). Greenwich, CT: Jal Press.

Thordardottir, E T., and Ellis Weismer, S. (2002). Verb argument structure weakness in specific language impairment in relation to age and utterance length. Clinical Linguistics and Phonetics, 16, 233-250.

Treiman, R. (1991). Children's spelling errors on syllable initial consonant clusters. Journal of Educational Psychology, 83, 346-360.

Treiman, R., and Bourassa, D.C. (2000). The development of spelling skills. Topics in Language Disorders, 20, 1-18.

van der Lely, H.K.J., and Christian, V. (2000). Lexical word formation in children with grammatical SLI: A grammar-specific versus an input-processing deficit? Cognition, 75, 3363.

van der Lely, H.K.J. and Ullman, M.T. (2001). Past tense morphology in specifically language impaired and normally developing children. Language and Cognitive Processes, 16, $177-217$.

Watkins, R., Rice, M. L., and Moltz, C. (1993). Verb use by language-impaired and normally developing children. First Language, 13, 133-143.

Wells, G. and Chang, G.L. (1986). From speech to writing: some evidence on the relationship between oracy and literacy. In A. Wilkinson (Ed.), The Writing of Writing (pp. 109-131). Milton Keynes, UK: Open University Press.

Westby, C., and Clauser, P. S. (1999). The right stuff for writing: Assessing and facilitating written language. In H. Catts and A. Kamhi (Eds.), Language and Reading Disabilities (pp. 259-313). Boston; London: Allyn and Bacon. 
Windsor, J., and Hwang, M. (1999). Children's auditory lexical decisions: A limited processing capacity account of language impairment. Journal of Speech, Language and Hearing Research, 42, 990-1002.

Windsor, J., Scott, C. M., and Street, C. K. (2000). Verb and noun morphology the spoken and written language of children with language learning disabilities. Journal of Speech, Language and Hearing Research, 43, 1322-1336. 


\section{Acknowledgements}

This research was conducted in partial fulfilment for a Masters degree supported by an Economic and Social Science Research Council awarded to Clare Mackie. Thanks are due to all the children who took part, to Moor House School, Oxted for their continued support in research and Dr V. Connelly, Susan Ebbels, Professor G. Lindsay and two anonymous reviewers for constructive critical comments. 
Table 1.

Results of Standardised Tests Used for Identification and Matching

\begin{tabular}{|c|c|c|c|}
\hline & $\begin{array}{l}\text { SLI Group } \\
(N=11)\end{array}$ & $\begin{array}{l}\text { CA Group } \\
(N=11)\end{array}$ & $\begin{array}{l}\text { LA Group } \\
(N=11)\end{array}$ \\
\hline \multicolumn{4}{|c|}{ Bus story Information Raw score } \\
\hline Mean $(S D)$ & $29.82(4.64)$ & $32.82(4.90)$ & $26.73(6.60)$ \\
\hline Range & $18-34$ & $23-40$ & $16-34$ \\
\hline \multicolumn{4}{|c|}{ Bus Story Sentence Length Raw score } \\
\hline Mean $(S D)$ & $10.2(1.44)$ & $14.26(2.71)$ & $9.25(2.15)$ \\
\hline Range & $7.4-12.6$ & $11-19.2$ & $5.1-13.6$ \\
\hline \multicolumn{4}{|c|}{ WORD Standard score } \\
\hline Mean $(S D)$ & $72.45(9.10)$ & $96.27(11.77)$ & $99.27(6.83)$ \\
\hline Range & $59-92$ & $83-111$ & $89-117$ \\
\hline \multicolumn{4}{|c|}{ Raven's Matrices Raw score } \\
\hline Mean $(S D)$ & $31.36(3.35)$ & $29.91(2.55)$ & $30.43(1.72)$ \\
\hline Range & $25-35$ & $26-34$ & $28-33$ \\
\hline \multicolumn{4}{|c|}{ CELF-R: Standard score } \\
\hline Mean $(S D)$ & $65.91(10.45)$ & - & - \\
\hline Range & $50-85$ & & \\
\hline
\end{tabular}

Note. Dashes indicate that the test was not completed 
Table 2.

Performance on the Writing Task: Length, Syntax Errors, Spelling Errors, Content and Fluency

\begin{tabular}{llll}
\hline SLI Group & CA Group & LA Group & $p$ \\
$(N=11)$ & $(N=11)$ & $(N=11)$ & \\
\hline
\end{tabular}

Total number of words

$\begin{array}{lllll}\text { Mean }(S D) & 39.9(30.49) & 91.0(33.86) & 53.18(32.89) & .003 \\ \text { Range } & 3-124 & 49-173 & 20-130\end{array}$

Proportion of syntax errors

$\begin{array}{lllll}\text { Mean }(S D) & .194(.172) & .017(.014) & .040(.033) & .001 \\ \text { Range } & .00-.67 & .00-.04 & .00-.11 & \end{array}$

Proportion of spelling errors

$\begin{array}{lllll}\text { Mean }(S D) & .156(.185) & .031(.031) & .162(.127) & .007 \\ \text { Range } & .00-.60 & .00-.09 & .00-.26\end{array}$

Fluency (Words per minute)

$\begin{array}{lllll}\text { Mean }(S D) & 3.23(2.44) & 7.94(4.27) & 3.69(2.40) & .002 \\ \text { Range } & 0.15-8.27 & 4.45-18.60 & 1-8.60\end{array}$

Content

$\begin{array}{lllll}\text { Mean }(S D) & 9.09(3.96) & 14.55(5.07) & 12.36(4.84) & .042 \\ \text { Range } & 4-18 & 7-12 & 7-19\end{array}$


Table 3

Correlations between Oral Language, Reading and Writing Measures for the SLI Group

\begin{tabular}{lllllllll}
\hline Measure & 1 & 2 & 3 & 4 & 5 & 6 & 7 & 8 \\
$(N=11)$ & & & & & & & \\
& & & & & & & \\
\hline 1. Bus Story Information & - & & & & & & \\
2. Bus Story Sentence Length & .52 & - & & & & & & \\
3. Word reading & .08 & .12 & - & & & & \\
4. Total words & -.17 & .0 .5 & .25 & - & & & \\
5. Content Score & .14 & .29 & -.28 & .58 & - & & \\
6. Proportion of syntax errors & .16 & .23 & .52 & -.11 & -.10 & - & \\
7. Proportion of spelling errors & .22 &.-21 & $-.82 *$ & -.11 & -.29 & -.53 & - \\
8. Fluency - words per minute & .25 & .26 & .58 & .48 & .10 & -.28 & -.35 \\
\hline * & & & & & & & \\
\hline
\end{tabular}

$*_{p}=<.006$ 
Table 4

Correlations between Oral Language, Reading and Writing for the CA Group

\begin{tabular}{|c|c|c|c|c|c|c|c|c|}
\hline $\begin{array}{l}\text { Measure } \\
(N=11)\end{array}$ & 1 & 2 & 3 & 4 & 5 & 6 & 7 & 8 \\
\hline 1. Bus Story Information & - & & & & & & & \\
\hline 2. Bus Story Sentence Length & .69 & - & & & & & & \\
\hline 3. Word reading & .26 & .09 & - & & & & & \\
\hline 4. Total words & -.02 & -.41 & -.52 & - & & & & \\
\hline 5. Content & -.06 & -.17 & -.72 & .76 & - & & & \\
\hline 6. Proportion of syntax errors & -.29 & -.38 & -.40 & .31 & .62 & - & & \\
\hline 7. Proportion of spelling errors & -.13 & -.19 & -.66 & .55 & .61 & -.16 & - & \\
\hline 8. Fluency- words per minute & .48 & .03 & -.04 & .51 & .55 & .45 & .09 & - \\
\hline
\end{tabular}


Table 5 .

Correlations between Oral Language, Reading and Writing for the LA Group

\begin{tabular}{lcccccccc}
\hline Measure & 1 & 2 & 3 & 4 & 5 & 6 & 7 & 8 \\
$(N=11)$ & & & & & & & & \\
\hline 1. Bus Story Information & - & & & & & & \\
2. Bus Story Sentence length & .77 & - & & & & & & \\
3. Word reading & .21 & .11 & - & & & & \\
4. Total words & .16 & .13 & .60 & - & & & \\
5. Content & .23 & .03 & .44 & .76 & - & & \\
6. Proportion of syntax errors & .06 & .41 & .32 & .27 & .19 & - & \\
7. Proportion of spelling errors & -.65 & -.41 & -.44 & -.05 & -.01 & -.03 & - \\
8. Fluency - words per minute & .39 & .42 & .40 & $.80 *$ & .62 & .31 & -.23 & - \\
\hline
\end{tabular}

$* P<.006$ 
Table 6.

Mean Results of Whole Word Errors as part of the Syntax Scale

\begin{tabular}{cllll}
\hline & SLI Group & CA Group & LA Group & $p$ \\
& $(N=11)$ & $(N=11)$ & $(N=11)$ & \\
\hline Addition errors & & & & \\
Mean $(S D)$ & $.029(.032)$ & $.001(.003)$ & $.025(.026)$ & .005 \\
Range & $.00-.10$ & $.00-.01$ & $.00-.09$ & \\
Omission errors & & & .006 \\
Mean (SD) & $.100(.191)$ & $.009(.011)$ & $.004(.007)$ & \\
Range & $.00-.67$ & $.00-.03$ & $.00-.02$ & \\
Substitution errors & & & $.008(.010)$ & \\
Mean (SD) & $.023(.033)$ & $.004(.008)$ & .003 & \\
Range & $.00-.10$ & $.00-.02$ & $.00-.03$ &
\end{tabular}


Table 7.

Mean Results of Word Ending Errors as Part of the Syntax Scale.

\begin{tabular}{cllll}
\hline & SLI Group & CA Group & LA Group & $p$ \\
& $(N=11)$ & $(N=11)$ & $(N=11)$ & \\
\hline Addition errors & & & & \\
Mean $(S D)$ & $.002(.007)$ & $.002(.004)$ & - & \\
Range & $.00-.02$ & $.00-.01$ & - & .022 \\
Omission errors & & & & \\
Mean (SD) & $.041(.064)$ & $.002(.005)$ & $.001(.004)$ & \\
Range & $.00-.17$ & $.00-.02$ & $.00-.01$ & \\
Substitution errors & & & & \\
Mean (SD) & - & & & \\
Range & & & &
\end{tabular}

Note. Dashes indicate that that group produced none of this particular type of syntax error 


\section{Appendix A}

Extract of Bus Story transcripts for all three groups

\section{SLI group}

Once upon a time there was a naughty bus and he broke down and the driver fixed him but he ran away on the way he met a train and he was very angry he was trying to beat him but he went through the tunnel and on to the town He was going to try to run over people and they just quickly ran out of the way he was still on the road

\section{CA group}

Once upon a time there was a bus driver he was trying to mend it but the bus ran away on the way he met a train they are all racing and making funny faces at each other the train was a bit of a person who never liked losing so he went under the tunnel the bus went into town the bus was in the city and the policeman blew his whistle and said stop he ran people over

\section{LA group}

Once upon a time there was a naughty bus the naughty bus ran away and then he meets a train and they make funny faces and then the train went into a tunnel and the bus felt all alone he met a policeman and the policeman blew his whistle and is shouting 'stop, stop' 
Appendix B

Sample writing pieces

SLI group

The boy play where his toy

The boy is sitting on table

The boy is 5 years old

The boy is play where old toy

The boy like football

\section{CA group}

There is a boy in this picture and he is making a movie with his toys. He is concentrating hard and careful. He is living in a very old house long ago with toys on the table. He seems to be very quiet and must be talking in his head. It looks as though that he is interested in making up movies, with his toys. The boy looks very young and does not have a school to work in, however; he does have books on the shelf beside him. He looks very sad and seems lonely because he looks like he does not have any friends.

\section{LA group}

One day a boy was playing with his toys and he had a ghost friend and the ghost friend was called Bob and the boy was called Jamie and they lived together in a big house with 6 bedrooms and they can almost fit a dozen cow in it. One day the boy went to bed a dreamed that he had a dozen cows. He went down to the kitchen and in the kitchen there was a dozen cows. 